\title{
Research on Industrial Transformation and Upgrading of Gannan Original Central Soviet Area Based on Symbiosis
}

\author{
Xiaoyong Huang \\ Finance Institute \\ Jiangxi Normal University \\ Nanchang, China \\ Xidu3721@sina.com
}

\author{
Zhonghou Cheng \\ Finance Institute \\ Jiangxi Normal University \\ Nanchang, China \\ 1291457969@qq.com
}

\author{
Rongqiu Huang \\ Finance Institute \\ Jiangxi Normal University \\ Nanchang, China
}

\begin{abstract}
Transformation and upgrading is the inevitable requirement of regional economic development under the new normal of Chinese economy, and also the key to the sustainable development of industry. Since Gannan original central Soviet area revitalization plan for five years, the economic growth rate is very fast, but the level of industrial transformation and upgrading is low. The economic growth rate of the former Central Soviet Area of Gannan was in the leading position of the first square array in Jiangxi Province, and the level of industrial transformation and upgrading was in the backward position of the third square matrix. In view of this situation, this study through the field research, interview records, questionnaires and other forms of the Gannan original central Soviet area industrial transformation and upgrading of the current results of the detailed sorting, so as to further excavate the Gannan original central Soviet area industrial transformation and upgrading of the face dilemma and reason. On the basis of the above, this study is based on the symbiosis perspective, and puts forward the countermeasures and suggestions to upgrade the industrial transformation and upgrading of the former Central Soviet Area in southern Jiangxi province, and achieve the goal of promoting the overall rise of the old revolutionary base areas and raising the living standard of the old revolutionary old liberated areas.
\end{abstract}

Keywords-Gannan original central Soviet area; transformation and upgrading; symbiotic perspective; countermeasures and suggestions

\section{INTRODUCTION}

Since the 18th National Congress, the state has attached great importance to the work of the economic development of the old revolutionary areas and people's lives. Gannan and other former Central Soviet Area as a member of the old revolutionary base areas ushered in a good opportunity for development. In order to thoroughly implement the central policy, the Jiangxi Provincial Party Committee 13th Plenary Session put forward the "development and upgrading, well-off speed, green rise, hard work", the "development and upgrading" in the first place. On April 10, 2014, the second meeting of the former Central Soviet Area Revitalization Development Leading Group was held in Nanchang. Provincial Party Secretary stressed that to speed up the revitalization of the original Central Soviet area development; the key is to stimulate endogenous motivation. To focus on the idea of "waiting to be", to correctly handle the relationship between support for and self-reliance, "blood transfusion" and "hematopoietic". To give full play to resources, agriculture, ecology and other advantages, and vigorously enhance the level of urbanization, efforts to promote the development and upgrading. In June 2015, the province is determined to revitalize 30 key development platforms of Gannan and other former Central Soviet Area, to expand the effect of the industry revitalization of the former Central Soviet Area,and upgrade to develop into an important strategic thinking to guide industrial transformation and upgrading of Gannan and other former Central Soviet Area. On July 9, 2015, the secretary Qiangwei held a leading cadres of the General Assembly in Ganzhou City to further emphasize the 16-character principle of Jiangxi development, and put forward the "seize the big opportunity to do big business, promote the development of" three requirements. In order to promote the industrial transformation and upgrading of the former Central Soviet Area in Gannan and other areas, the project team continued to develop in depth from October 2016 to March 2017, and went to Ganzhou City, Shicheng, Ningdu, Taiyu, Guangchang, Cixi and other counties conducted a survey, collected and sorted the relevant data over the past five years on industrial development of Gannan and other former Central Soviet. Research shows that the revitalization of the Central Soviet Area of southern Jiangxi Province over five years, the people of the Soviet Union has brought greater benefits and higher happiness index, rural residents per capita income growth. However, we have to realize that Gannan and other central Soviet areas only to enhance the economic growth and per capita income level, but the level of industrial transformation and upgrading is not high. 
To promote the sustainable development of the industry, enhance hematopoietic function, need to take the transition path of symbiotic transformation.

\section{AN ANALYSIS OF THE CURRENT SitUATION OF} INDUSTRIAL DEVELOPMENT AND UPGRADING IN THE FORMER CENTRAL SOVIET AREA OF GANNAN

\section{A. The Achievements of Industrial Development and Upgrading in the former Central Soviet Area of Gannan}

According to the principle of typology, global nature and difference, this study focuses on the comprehensive scientific analysis of Gross National Product (GDP), industrial added value and investment in fixed assets in Ganzhou, Ji'an and Fuzhou.

From the perspective of GDP growth, Ganzhou, Ji'an and Fuzhou GDP growth were 10\%, 10.2\%, 9.8\%, ranking in the province were the third, second and sixth, Nanchang and Jiujiang City respectively In the sixth and first place, the growth rate has surpassed Nanchang, second only to Jiujiang, the above indicate that Ganzhou, Ji'an and Fuzhou under the implementation of strategic planning of the revitalization of the central Soviet area has achieved strong results, economic growth momentum is very strong.

From above-scale industrial added value, the Above-scale industrial added value of Ganzhou, Ji'an and Fuzhou were $12.4 \%, 12.5 \%, 11.7 \%$, respectively, ranked third in the province, the first and seventh, while Nanchang City and Jiujiang City, respectively, ranked sixth and first, this indicator has been more than the growth rate of Nanchang and Jiujiang City, all indicate that Ganzhou, Ji'an and Fuzhou has made a great development in industrial development, especially in the industrial sector.

From the fixed asset investment, fixed assets investment of Ganzhou, Ji'an and Fuzhou growth were 20.9\%, 19.4\%, 19.9\%, fixed assets investment of Ganzhou in the province ranked first, more than $20.2 \%$ of Jiujiang and $18.6 \%$ of Nanchang, which also shows that the former Central Soviet Area of Gannan is the implementation of the national strategy of the support projects, and to promote the speed is very fast, reinforce the development foundation.

\section{B. Comprehensive Evaluation on the Industrial Development and Upgrading of the former Central Soviet Area of Gannan}

Since the revitalization of the Soviet Union's strategy for five years, the economic growth rate of the former Central Soviet Area in southern Jiangxi was very fast, but there was also the pressure of industrial transformation and upgrading. This study constructs the evaluation index system of industrial transformation and upgrading by designing the annual output value of the industry, the annual cost of the industry, the annual income of the industry, the technological innovation of the industry, the contribution rate of the industry to the GDP and the innovation of the industry management. Composite index evaluation criteria are divided into 0-10, the higher the score, the better the degree of industrial transformation and upgrading. Through the calculation, Ganzhou City for the 5.1, Ji'an City,
5.5, Fuzhou, 4.8, the average of Ganzhou, Ji'an and Fuzhou is 5.1; and Nanchang City, 6.7, Jiujiang City, 6.3, Pingxiang City, 5.9, Yichun City, 5.7, the average of Nanchang, Jiujiang, Pingxiang, Yichun is 6.2, much higher than the level of the original Central Soviet Area of southern Jiangxi. In the industrial transformation and upgrading, Nanchang and Jiujiang City in the first square array, Pingxiang, Yichun, Ji'an, Shangrao belong to the second phalanx, Ganzhou, Xinyu, Jingdezhen, Fuzhou belongs to the third phalanx, that is, in addition to Ji'an City, the original Central Soviet Area of southern Jiangxi in the third square array, industrial transformation and upgrading of pressure, heavy task.

From the results achieved and comprehensive evaluation can be seen, the original Central Soviet Area of southern Jiangxi's economic growth rate in the first square array of the leading position in Jiangxi Province, while the industrial transformation and upgrading level is in the third matrix behind the situation. To this end, in the future economic development as much as possible to deal with economic growth and industrial transformation of the contradictions and problems.

\section{AN ANALYSIS OF THE DILEMMA OF INDUSTRIAL}

TRANSFORMATION AND UPGRADING IN THE FORMER CENTRAL SOVIET AREA OF GANNAN

\section{A. Industry concentration is not high, the cluster level is low}

Industry is highly concentrated and cluster, is to ensure that the industry play a "scale effect" and "cluster effect" of the inevitable premise. From the current situation, Gannan Central Soviet industry overall concentration is not high, the cluster level to be improved. Gannan agricultural industry presents a large industry, small-scale phenomenon. [1] For example, Gannan navel orange cultivation of small-scale family-based, low proportion of large-scale cultivation, single Orange business model, the integration level is not high; and tungsten and rare earth mining area of Ganzhou are many and small, less one hundred billion enterprise, resource extraction the overall low utilization level; the scale effect of touch industrial industry in Ji'an is not obvious, the size of backboneof firm is significantly smaller; Fuzhou Industrial Park are isolated, there is no advantage of the formation of the industry, from the cluster layout is still a big gap, the industry spill effect is not strong.

\section{B. Resource carrying capacity is limited, lack of continuity}

The leading industry of Ganzhou City is the development of mineral resources, however, due to extensive extensive mining, resulting in serious supply and demand imbalance. In other words, the capacity of mineral resources is difficult to meet the industry to the depth of the level of development, resulting in economic and social development of the "fault" phenomenon; the key is not able to do the industry's existing development and future transformation of the transition work. Ji'an key development industry is mainly concentrated in the field of labor-intensive industries and heavy chemical industry, including machinery manufacturing, pharmaceutical and chemical, metallurgical and building materials, etc., obviously, these industries have high consumption, high input, high pollution, low efficiency and other characteristics, Lack of 
sustainable development potential. Wang Xuejun and other based on GIS Ganzhou resources and environment carrying capacity of the evaluation research, with the support of GIS software, to achieve terrain topography, land use, forest resources, ecological environment, socio-economic and other 12 index factor spatial map data valid registration, statistical analysis and map algebra operation appraisal model of resources and environment carrying capacity. [2] The evaluation results show that the status of Ganzhou City resources and environment carrying capacity is not optimistic, has been close to the critical environment of environmental capacity.

\section{The overall industry chain is not long, the lack of deep processing technology}

The main problem of tungsten mining in Ganzhou is as follows: First, the final processing of low-tech products. Second, the mining industry investment cycle is long. Third, the extensive development of mineral resources, resulting in a lot of waste of resources.To Dayu County as an example, since April 2013, Dayu County was classified as the national heavy metal pollution prevention and control demonstration area, the face of internal industry structure extensive multi-industry, multi-industry energy consumption and pollution, many primary products, single enterprise of many other issues, eliminate backward production capacity of heavy task to achieve the goal of supply-side structural reforms urgently. At present, the proportion of non-mining industry in the industry has been increasing, but the overall scale is small, the industry grade is low and the technology content is still limited. The main problems of the touch industry in Ji'an City: First, there is no industrial chain support. Lack of industrial chain, industrial collaboration supporting capacity is very low. Second, the development of modern service industry supporting the development of the manufacturing industry is lagging behind. Has been put into operation the main business income of lowkey enterprises, about 20 million, and the size of the backbone enterprises significantly smaller. In the actual survey to understand that the existing touch industry in Ji'an City, the upper and lower reaches and the surrounding products, only 23 enterprises, more difficult to form the industrial chain.

\section{Industry linkage lag, open economy low level}

For Ganzhou, due to institutional and system reasons, each county (or city) government competition is often more than cooperation, and sometimes compete for resources for the vicious competition of internal friction phenomenon. At the same time, Ganzhou City was lacking in strategic development of industrial thinking, failed to effectively use the location advantages, simply set the prospects for industrial development in the local area, and only focus on building a platform to undertake industrial transfer, this "nest" Industry linkage lag. According to the preliminary research data, the comprehensive analysis shows that the level of Gannan industry linkage development is obviously lower than that of Changjiu plate, and its open economic development level is only 5.2 in $0-10$ points, while the Changjiu plate score is 7.5 , developed area the average level of around 8.9. Description industrial linkage development and economic openness levels, Gannan former Central Soviet Area is obviously behind.

\section{E. Industrial ecology backward, environmental problems worrying}

Ganzhou resource industry mining is very extensive, low efficiency of resource use, a great impact on the ecological environment. Some industrial parks and heavy pollution enterprises mixed with low-pollution enterprises which increase the industrial "three wastes" resource utilization, has led to a continuous decline in environmental safety and environmental quality deteriorated. [3] Fuzhou and even some parks in order to complete the "target”, for "performance some parks even move high energy consumption, high pollution projects to the industrial park. Ganzhou City, the proportion of industrial waste water emissions accounted for about $15 \%$ of the total industrial emissions accounted for the proportion of the province about $13 \%$ of the general industrial solid waste production accounted for about $8 \%$ of the province, and Ganzhou City, energy consumption the total number of the province ranked fifth, indicating pollution and energy consumption showed double high phenomenon.

\section{F. Industrial structure is single, homogeneous competition is fierce}

Many counties of Ganzhou City have tungsten ore, rare earth, navel orange as a pillar industry, easy to form market saturation, resulting in competition with the industry. Gannan navel orange distribution in Ganzhou City, more than 20 counties, the lack of effective coordination between the county mechanisms, in science and technology services, pest management, unified management and other aspects of the existence of a larger problem; and tungsten and rare earth resources rich county, Did not do dislocation development, regarded it as a "cash cow", resulting in a single industrial structure, homogenization, ignoring the sustainable development of the industry. The majority of enterprises in Ji'an City are still dominated by a single intermediate product, the advantages of high-end machine products are less, the software and information services industry lagging behind, the modern service industry based on Internet + is lagging behind and can't integrate the upper, middle and lower reaches, The formation of diversified, multi-system industry chain. Fuzhou City, due to the same industry scattered in various parks, which in turn caused the industrial structure of the park convergence phenomenon, it is difficult to form the industrial chain and economies of scale, while increasing the difficulty of integration, so that although the number of industrial enterprises in Fuzhou, the province's 10\%, But its single distribution of the industry can't reflect the competitive advantage, the lower the synergy value

\section{REFERENCES}

[1] Huang Zheming, "Spatial and Temporal Differentiation of the Rural Eco - economic System in the Central Soviet Area of Southern Jiangxi Province," Jiangxi Normal University. June, 2015(In Chinese).

[2] Wang Xuejun, Fu Xiao et al., "Evaluation of GIS Ganzhou Resources and Environment Carrying Capacity Based," Jiangxi Agricultural University. December, 2013(In Chinese).

[3] Zhang Peng, "Increase Energy Saving Efforts to Promote Economic Restructuring and Upgrading - Gannan and Other Central Soviet Energy 
Consumption and Energy Saving Analysis," Energy Research and Management. September, 2015(In Chinese).

[4] Hu Zonghong, "Let the Gannan Soviet Region Simultaneously Build A Comprehensive Well - off Society - in - Depth Study and Practice the General Secretary of Xi Jinping about the Original Central Soviet Area of Southern Jiangxi Revitalized the Development of Ideas," Old Area Construction. May, 2015(In Chinese).

[5] Gao Xiaoqiong, "Financial Support for the Development and Rejuvenation of the Southern Jiangxi Province," Finance and Economy. November, 2011(In Chinese).
[6] Wei Jianmei, Li Qing, "SWOT Analysis of Southern Jiangxi and Other Central Soviet Characteristics of Agricultural Development Strategy," Hunan Agricultural Science. December, 2014(In Chinese)

[7] Liu Shanqing, Ke Fang, etc., "Former Central Soviet Status Quo Jiangxi Industrial Layout Analysis," Business Jiangxi Normal University. October, 2012(In Chinese).

[8] Chen Yunping, Huang Xiaoyong, "Pan-county Economy City Integration Symbiosis: Evolutionary Logic, Theoretical Deconstruction and Industrial Path," Macroeconomic Research. April, 2016(In Chinese). 